\title{
El servicio al cliente como estrategia competitiva
}

\section{Customer service as a competitiveness strategy}

Alberto Morales Ospina*

Como citar este artículo

Morales, A. (2019). El servicio al cliente como estrategia competitiva. Revista Colombiana de Ciencias Administrativas. 1(1), pp. 8-20. Recuperado a partir de http://cipres.sanmateo.edu.co/index.php/rcca

* Profesional en Ciencias Militares, Magister en Seguridad y Defensa Nacionales, candidato a doctor en Ciencias de la Educación. Correo electrónico: amoraleso@sanmateo.edu.co 


\section{Resumen}

El artículo tiene como objetivo identificar la importancia del servicio al cliente en las organizaciones para visualizar el peso que tiene como criterio de evaluación en la toma de decisiones. El servicio al cliente se ha visto como un evento en segundo plano, sin embargo, desde la segunda mitad del siglo XX, después de eventos catastróficos para la humanidad, ha logrado escalar en el grado de importancia; tanto así que es de suma relevancia en todo el contexto organizacional. Por último, el presente texto se orienta desde el punto de vista cualitativo y descriptivo que enfoca la investigación con un concepto crítico y evaluativo.

Palabras clave: servicio al cliente; estrategia organizacional; marketing social

\section{Abstract}

The article aims to identify the importance of customer service in organizations to visualize the weight it has as an evaluation criterion in decision making. Customer service was always seen as a background event, but since the second half of the twentieth century, after catastrophic events for humanity, it has escalated in the degree of importance, so much so that it is of utmost relevance in the whole context organizationally. Finally, the present paper is focused on a qualitative and descriptive point of view that focuses research with a critical and evaluative concept.

Keyword: customer service; organizational strategy; social marketing

\section{Introducción}

El servicio al cliente se ha convertido en parte fundamental de cualquier organización. Sin embargo, desde antaño se ha visualizado de manera subjetiva, como parte de un saber popular que traslada a la experiencia. Así se ha manejado por muchos años, tanto así que solo hasta mediados del siglo XX toma realmente importancia en el mundo de los negocios. Poco a poco ha ido ganando un puesto de análisis entre los altos ejecutivos, quienes ven un futuro exitoso orientados en un servicio al cliente eficiente y eficaz.

El propósito de este artículo es entender cómo la visión estratégica de las organizaciones, la cual es de suma importancia en la toma de decisiones de alto nivel, tiene como factor predominante el servicio al cliente, criterio de peso en el ejercicio de planeación a largo plazo organizacional. 
La visualización de un servicio efectivo en una organización se convirtió en el norte de este proyecto. Permite comprender la importancia estratégica del servicio en los resultados alcanzados. En otras palabras, es ver el servicio como una cultura que llevará a la organización por el camino del éxito.

\section{Metodología}

El presente artículo de reflexión, de acuerdo con la modalidad, es un proyecto de desarrollo. El documento presenta los resultados desde una perspectiva analítica, interpretativa y crítica, acerca del servicio al cliente. Por su naturaleza, es una investigación cualitativa; busca examinar el problema mediante la comprensión hermenéutica y el análisis de resultados, al ver el servicio al cliente como ventaja competitiva. Por lo anterior, la investigación, de acuerdo a su objetivo, es un estudio evaluativo, explicativo y descriptivo.

Es una investigación evaluativa porque se refiere a un análisis de la eficacia, eficiencia y el impacto que tiene el servicio al cliente en las organizaciones. Es una investigación desde la óptica del problema evaluativa, porque se busca visualizar la efectividad de aplicar procesos de servicio al cliente en las organizaciones. Con relación a la fuente, es una investigación de tipo documental, se basa en la revisión de diferentes proyectos relacionados con el tema en cuestión.

\section{Resultados}

El servicio al cliente toma importancia en el escenario organizacional poco después de terminada la segunda guerra mundial. De este evento catastrófico, que inundó de dolor y angustia el mundo entero, surgen las necesidades que de manera lógica empiezan a sentirse obvias y vitales de subsanar.

El nacimiento de nuevas empresas y el fortalecimiento de muchas más existentes son la respuesta que da el mundo de occidente a estas necesidades. En Estados Unidos la guerra no afectó la infraestructura industrial. Este es el país llamado a dar la mano al mundo con sus productos, con su desarrollo y su tecnología. En ese momento, y más que cualquier otro, Europa necesita de la mano solidaria de Norteamérica.

Lógicamente, los industriales norteamericanos ven la oportunidad de negocio más grande hasta el momento. La competencia empieza a verse de manera frontal y abrupta, los productos que necesita Europa 
son básicos y la demanda es alta. Aquí es donde los industriales norteamericanos van a encontrar un mercado global, demandante, exigente y necesitado. Así, la oferta debe empezar a diferenciarse entre sí para ser competitivos.

Por lo anterior, Dalongaro y Froemming (2012) hacen una acotación al respecto, hablan de añadir valor al producto ofertado:

Añadir valor al producto es darle características que no le son comunes. Trasladarlo al cliente es la estrategia adecuada en el segmento de ventas. La forma en que será recibido dicho aumento de valor, sin embargo, puede variar mucho de un cliente para otro (por ejemplo, descuentos en los precios) a otro (por ejemplo, atención personal) y, todavía, a otro (por ejemplo, el acceso a la información) (p. 938).

En el 2012, Dalongaro y Froemming van un poco más allá. No solo se da valor agregado al producto en sí, además, se da valor al servicio. Este será percibido por el cliente de manera directa, eficaz y oportuna. Así, más adelante se convertirá en el punto de quiebre en las decisiones futuras del cliente.

De acuerdo a las necesidades que presenta la demanda, en la segunda parte del siglo XX, se vislumbra una sociedad con gustos diferentes a los que se tenían antes de la guerra. Una sociedad más madura y más consciente de su entorno, similar a lo que sucedió después de la peste negra, que mató a dos tercios de la población mundial. Esto provoca el surgimiento de una época llamada Renacimiento, un mundo alejado de las banalidades de la vida y más centrado en lo práctico, lo útil, lo necesario.

Pero el ser humano es de memoria a corto plazo y olvida rápidamente su fragilidad como especie atacada por la peste y caída en la vanidad. Solo las dos guerras mundiales lo despiertan y le recuerdan, de manera violenta, que el ser humano es frágil y necesita muchas cosas para subsistir. La vida en comunidad, por ejemplo, es lo único que las puede garantizar.

La cultura siempre ha sido la fuerza que une al ser humano como especie. Sus costumbres, sus tradiciones, sus necesidades, serán siempre colectivas. Desde este punto de vista se genera una cultura organizacional, que pronto se manifiesta en vertientes que van a influenciar dichas comunidades, en torno a una marca, a una moda y a un estilo de vida.

Los estadounidenses, conscientes de ello, invierten recursos y esfuerzos para posicionar su país como el ideal para cualquier ser humano. 
Esto causa la mayor migración mundial hacia su país. Sin embargo, los que no podían realizar tan largo viaje, trataban de moldear su entorno lo más parecido al estilo de vida de América del Norte.

La cultura organizacional desemboca en un servicio al cliente, que no solo va a ser responsabilidad de algunos miembros, es responsabilidad de todos y de cada uno de los miembros de cualquier organización. Para lograr cimentar una cultura eficiente, se hace necesario identificar factores críticos de éxito, que involucren a todos sus integrantes de manera carismática mas no impuesta.

"Cabe destacar que en toda organización existen factores internos que generan una cultura. Sin embargo, el origen de la cultura de servicio se debe al esfuerzo de las empresas por orientar todos sus factores internos hacia el servicio del cliente" (García, 2016, p. 388).

En el 2016 García, en un artículo publicado, da a entender que la cultura del servicio ha sido fruto de innumerables esfuerzos de las organizaciones que entendieron que el cliente es su miembro más importante y más inestable. Por otro lado, no solo en Estados Unidos se ha notado la importancia que tiene el servicio al cliente dentro de su estrategia de negocio. Además estudios, como el de Daza (2017), han determinado que toda nación depende de la capacidad de su industria para reinventarse continuamente. Esto incluye la dependencia que se tiene con la fidelización de los clientes, basados en una oferta abierta y abundante que invade el mercado desde muchas ópticas.

Igualmente, en su obra describe cómo la diferenciación hace que una organización subsista de manera adecuada en un entorno altamente competitivo y despiadado. Allí, los débiles que se aferran a paradigmas insulsos, están condenados a desaparecer y solo los más innovadores y diferenciadores tendrán oportunidades de éxito.

Asimismo, discute que la competitividad de una nación depende de la capacidad de su industria para innovar y mejorar. También afirma que las empresas obtienen ventajas competitivas si consiguen innovar, y que las estrategias ganadoras no son aquellas que tratan de hacer mejor a una empresa, sino aquellas que la hacen diferente (Daza-Rodríguez, 2017, p. 24).

En un mundo tan heterogéneo, es lógico que el servicio también lo sea. El servicio al cliente no puede convertirse en una camisa de fuerza para la organización. Debe tener capacidades importantes de cambio, de flexibilidad y de adaptación. Es allí donde Daza hace énfasis en la diferenciación, la cual marcará el camino al éxito de la organización. 
La globalización ha traído diferentes culturas, costumbres, tradiciones, las cuales demandan productos que solucionen sus necesidades. No obstante, no se puede abordar a todas las personas de la misma manera, se debe tener un factor diferencial que procure subsanar de la mejor manera las necesidades de todas y cada una de las personas. El servicio al cliente, dentro de su heterogeneidad, es el punto más importante a la hora de ejecutar las estrategias organizacionales, las cuales hacen parte de las habilidades gerenciales que debe adquirir un directivo de alto nivel.

Como es de notar, las habilidades gerenciales se aprenden, se inculcan y se desarrollan. En este sentido, la academia toma un puesto de importancia en el momento en que el estudiante adquiere estas cualidades. La universidad ha determinado la necesidad de la sociedad de tener profesionales más proactivos y más incluyentes en el momento de implementar estrategias organizacionales.

Sanz del Vecchio et al. (2017) escriben acerca de estos aspectos. Determinan que la universidad no solo difunde de manera académica la manera de hacer un buen mercadeo, sino que lo aplica a su propia organización como parte de las estrategias en la vinculación y permanencia de sus estudiantes.

En muchas universidades, sean públicas o privadas, las estrategias de marketing se han vuelto sustanciales para ofrecer un servicio al cliente cada vez más exigente y de acuerdo a las necesidades específicas del interesado, es así como se ha desarrollado un servicio más eficaz (p. 140).

Los estudios de mercado de las universidades no solo han servido para enfocar las diferentes mallas académicas, también han servido para su propio desarrollo organizacional. Enfatizan esfuerzos de crecimiento constante y diferencial, haciéndolas más incluyentes y determinando un servicio al cliente mucho más estratégico en la toma de decisiones gerenciales.

Dentro de los resultados que se han obtenido por parte de la academia, es determinante la programación neurolingüística. Por ello, se trata de mantener un lenguaje más amable, que influya en el usuario final de tal manera que se sienta parte de la organización y no solamente un cliente. Por ende, se usan términos mucho más cálidos y cordiales, por ejemplo, palabras como colaborador y nombres de dependencias como servicio al estudiante.

Este tipo de actividades, a la larga, se convierten en estrategias de mercado. El servicio al cliente toma gran importancia en las decisiones gerenciales. Pero no todo está afuera, así como la academia logra 
determinar la manera de afrontar el servicio como parte de su estructura y como parte de su producto, las organizaciones que están en contacto con el ciudadano común observan que el primer cliente al cual deben brindar un buen servicio está dentro de su organización. De allí nace el endomarketing del cual nos habla Faría, Salazar y Castellano (2017) de manera más amplia en su artículo, llevando al lector a ver desde otra óptica el servicio al cliente.

Al hablar de estrategias se empieza a acotar sobre las directrices por las que se regirá una organización a modo de lograr sus objetivos propuestosy al asociarlas al Endomarketing, se definen como un programa intensivo enfocado en el conocimiento del cliente interno, su capacidad, desarrollo, satisfacción oportuna y razonable de sus necesidades (p. 28).

La cultura organizacional es una estrategia de crecimiento organizacional, tiene como elemento determinante el servicio al cliente. Por su parte, el endomarketing es aplicado por las organizaciones como parte de sus estrategias con el fin único de comprometer a sus colaboradores, fortaleciendo su cultura organizacional y solo lo logran brindando un excelente servicio al cliente interno.

Cuando el servicio al cliente se practica de manera global, afecta positivamente a los colaboradores de la organización y a los clientes que se benefician de los bienes o servicios que ofrece la empresa. Así, es importante determinar cuál es la mejor forma de acceder a cada uno de ellos, esto hace parte de la investigación que debe realizarse. No obstante, no a todos se llega de la misma manera, siempre hay algo que debe cambiar, mejorar, o diferenciar el servicio. Esto hace sentir al cliente mucho mejor, lo hace sentir importante, lo hará volver en un futuro y si la estrategia es realmente efectiva, ese cliente no volverá solo, con él vendrán más clientes potenciales.

Uno de los referentes, Arellano (2017), determina que estas estrategias son canales dentro de los cuales se desarrollará todo lo determinante del servicio al cliente. De esta forma es que el incita a que el cliente tenga una percepción de alta calidad de los bienes o servicios que adquiere.

Los canales por los cuales se realizará el servicio deberán seleccionarse según la mejor forma de llegar al cliente y al cómo este pueda percibir la alta calidad del mismo y esto, dependerá de la estrategia de ventas, las características de cada cliente y la moda impuesta en el mercado (p. 75). 
Se han visto varios tipos de estrategia que puede desarrollar una organización. Así es como Arellano (2017) toma en cuenta la estrategia de ventas que no solo son estrategias de crecimiento, de cartera o de otro tipo, es toda estrategia en la que el servicio al cliente hace parte fundamental de su desarrollo e implementación, lo cual se focaliza en el cliente final y su percepción de la organización.

En un mundo que cambia tan rápido, que se transforma y crece de manera situacional, es importante tener en cuenta cómo la tecnología puede ayudar a implementar estrategias de servicio al cliente. Estas deben colaborar a que la imagen de la organización trascienda fronteras, no solo las geográficas sino también las generacionales, ya que no se puede obviar que hoy en día el cliente se define de acuerdo a la generación a la cual pertenece.

Isabel Blanco y María Segarra-Oña (2017), en una aproximación que realizan en uno de sus artículos publicados en la Universidad Pontificia Bolivariana, toman en cuenta la importancia que tiene el Marketing Online, basados en el crecimiento exponencial que ha tenido la tecnología, como las redes sociales que son capaces de movilizar grandes masas de personas. Este aspecto es fundamental en una estrategia de mercadeo basado en un servicio al cliente eficaz. Frente a esto, Blanco y SegarraOña (2017) mencionan:

El primer paso a dar antes de desarrollar estrategias de Marketing Online, es investigar los principales competidores que tienen presencia en la red (estudiar su página web, si tiene presencia en alguna red social, y la publicidad) y tomar de punto de referencia para su empresa (p. 33).

La tecnología se ha ganado su puesto de privilegio en el mundo, las redes sociales son su mayor exponente. Además, a través de estas, una organización puede crecer o destruirse. El prestigio, que durante años de trabajo duro se construye, esta a un solo clic de ser destruido. Las organizaciones no se pueden dar el lujo de brindar un mal servicio cuando el poder lo tiene el cliente desde su smartphone, su tablet o su pc.

Los clientes contemporáneos se empoderan de la tecnología para cada aspecto de su vida, desde encender un televisor en su hogar inteligente, hasta enviar información al otro lado del mundo. Así es como un mal servicio en el mantenimiento de un smartphone comprado en Colombia puede afectar las ventas de la empresa en Tokio cuando los clientes potenciales leen los comentarios en la red. 
Las herramientas tecnológicas se han convertido en armas de crecimiento o de destrucción en manos de adolescentes, adultos jóvenes y de una población en general cada vez más exigente. ¿Como lograr cambiar el enfoque que estas personas tengan al momento de usar la tecnología? solo hay una manera: generar una cultura organizacional que incluya el servicio al cliente como meta suprema de cada uno de los colaboradores de la organización, llevando así a que el usuario final tenga en sus manos un excelente producto y servicio que lo impulse a tener una óptica positiva de la organización.

La filosofía empresarial es vital para una empresa, puesto que esta es la base fundamental, considerada como el eje central y guía para las acciones que se realicen en pro de una organización, estas ligadas a la naturaleza y el propósito que mantienen, para ello es necesario establecer una cultura basada en lo que se quiera proyectar ante los clientes, así como normas que se quieran integrar como cultura corporativa dentro de una firma (Vera Campuzano \& Collins Ventura, 2018, p. 78).

Es necesario fortalecer la cultura organizacional, donde la filosofía empresarial debe estar muy bien fundamentada, con visión, proyección, misión, metas, logros, objetivos, que sean incluyentes y envuelvan de manera amena y armoniosa a todos los colaboradores, donde cada uno de ellos sienta como propia la organización. Lo anterior solo se logrará con un servicio al cliente interno bien enfocado y bien estructurado, para que cuando se implemente arroje resultados óptimos que se vean reflejados en un excelente producto y servicio al usuario final.

De alguna manera hay concordancia en lo expuesto por Campuzano y Collins (2018) y por Vanessa y Duarte (2018). A pesar de tratarse de documentos distintos, tienen grandes similitudes al referirse que el servicio al cliente se convertirá en una ventaja a la hora de competir, siempre y cuando las organizaciones le den la importancia que se merece este aspecto en su estructura empresarial.

En ambos documentos es notorio encontrar comentarios que identifican la idea de que el servicio al cliente es el factor diferencial en un mundo contemporáneo, cambiante y exigente, basado en el flujo de información actualizada y constante (Mojica Montoya, 2018). Esta información es de libre acceso para cualquier persona que posea un artefacto tecnológico que lo conecte a la red mundial de información, tanto de un producto en particular como de quienes lo producen, los precios, los comentarios etc. Así, el servicio al cliente marcará la diferencia entre tanta información a la que el usuario final tiene acceso. 
En una era de profundos cambios económicos políticos y sociales, las organizaciones enfrentan grandes retos, muchos de los cuales se encuentran relacionados con el incremento incesante en el número de competidores y el aumento de información en poder de los clientes haciéndolos más exigentes, convirtiendo al servicio al cliente en el factor diferenciador que permite a una organización alcanzar una ventaja competitiva en el mercado (Vanessa \& Duarte, 2018, p. 25).

El poder de convocatoria que se tiene usando herramientas tecnológicas, como lo son las redes sociales, se han tornado en armas de doble filo. Basados en ese flujo de información, se puede llegar a muchas personas en todo el mundo $y$, siendo una herramienta de marketing excepcional, también se puede convertir en la mejor forma de destruir la empresa si no se establece el servicio al cliente como la ventaja competitiva que realmente es.

Hasta el momento se ha ubicado el servicio al cliente como parte de la cultura organizacional, como parte de varias estrategias organizacionales, siempre buscando la ventaja sobre la competencia. Sin embargo, cabe mencionar que el servicio al cliente realmente es una estrategia competitiva independiente, es tan importante que ya no hace parte de ninguna otra, es por sí misma la estrategia que más ventajas va a traer a la organización. El servicio al cliente debe tener tanta importancia en la organización que sin una buena estrategia de servicio al cliente la organización se rezaga y pierde competitividad en el renglón económico en el cual se desarrolla.

Esta estrategia de servicio al cliente es altamente competitiva siempre y cuando no solo se focalice en el cliente externo, sino también en el cliente interno. Por ejemplo, cuando los colaboradores se sienten motivados dan todo de sí por la organización, alcanzan altos estándares de productividad, cometen menos errores, gastan menos tiempo en la producción, minimizando los defectos en el producto final, optimizando los recursos y convirtiendo al servicio al cliente, según a lo mencionado por Gutiérrez-Suárez, Sánchez y Garay (2019) en uno de sus artículos, en la estrategia competitiva más efectiva que cualquier organización pueda tener, llevándola a los primeros lugares en el colectivo imaginario de la población de clientes activos y potenciales.

En cuanto al desarrollo laboral se refiere que los aportes identificados en el tema de la productividad, eficiencia, eficacia y motivación percibido de manera objetiva como subjetiva en los colaboradores por parte de los gerentes, representarán una mirada más amplia a la hora de diseñar estrategias que permitan sostener dicho estado (Gutiérrez-Suarez, Sánchez, \& Garay, 2019, p. 10). 
Si la organización basa sus expectativas en el crecimiento constante y en el desarrollo tecnológico adecuado, debe tener en cuenta el cliente interno, es el real hacedor del éxito, bien dirigido, bien gerenciado. Para ello, los ejecutivos de alto nivel deben diseñar estrategias incluyentes en todo aspecto de la vida organizacional, como el factor humano, el factor de producción, el factor administrativo. Una vez cubierto lo anterior, estará el servicio al cliente, como estrategia competitiva de alto impacto económico.

La estrategia competitiva en tiempos de cambio, como lo es esta época contemporánea, se basa en el servicio al cliente. Allí se estructuran modelos competitivos de alto impacto, los cuales se deben ver reflejados en los estados financieros, concurriendo en filtros estadísticos que producirán análisis importantes en la toma de decisiones. Además, se basan en la información recolectada a través herramientas tecnológicas como los son las redes sociales.

Desde tiempos de mediados del siglo XX hasta nuestra época, el servicio al cliente se ha convertido en la mejor manera que tiene un gerente para alcanzar las metas de productividad generadoras de cambios y crecimiento organizacional, usándola como habilidad gerencial y constituyéndose como una estrategia competitiva de éxito.

\section{Conclusiones}

El servicio al cliente es la manera más eficaz que tiene una organización para ganar la fidelización de sus clientes. De esta manera se fija la marca en el colectivo imaginario y es así como se posiciona en un mercado exigente y audaz.

Toda industria basa su éxito en la capacidad de innovar, de crecer y de ser flexible. El aferrarse a paradigmas prefijados por una mentalidad conservadora, los llevará a ceder terreno en un mundo que cambia constantemente, donde sus exigencias son situacionales y, de la misma manera, la oferta debe portarse.

El endomarketing se convierte en la herramienta más efectiva de cualquier organización cuando ve la necesidad de fortalecer su cultura organizacional. Dicha cultura es la base de un servicio al cliente efectivo y global, que redunda en el sentido de pertenencia que cada miembro de la organización siente hacia la ella.

Las redes sociales son el canal de comunicación más rápido y eficaz de una sociedad consumidora. Basada en herramientas tecnológicas 
que facilitan su diario vivir, un buen servicio o uno malo, se hará viral en las redes sociales.

El servicio al cliente se establece como el factor diferencial que influye en la toma de decisiones del usuario final. En épocas contemporáneas, este usuario tiene acceso a información tanto de la propia empresa como de la competencia, la cual llega mediante herramientas tecnológicas, basando sus decisiones en los comentarios de satisfacción o insatisfacción de otros usuarios.

La estrategia competitiva más importante de cualquier organización es el servicio al cliente, haciendo énfasis en el cliente interno. Este será el que aumentará la calidad del bien o servicio ofrecido, minimizará inconformismos en el cliente externo $y$, de manera exponencial, aumentará la percepción de calidad del producto final en el colectivo de la sociedad, buscando la fidelización de la marca en el cliente.

\section{Lista de referencias}

Arellano Díaz, H. (2017). La calidad en el servicio como ventaja competitiva. Dominio de Las Ciencias, 3(2), 72-83. Recuperado de: https://dialnet. unirioja.es/servlet/articulo?codigo $=6093282$

Blanco, I. \& Segarra-Oña, M. (2017). Estudio exploratorio del uso del e-Marketing como estrategia para micro, pequeñas y medianas empresas de servicios. Puente (Universidad Pontificia Bolivariana), 7(2), 29-37. https://doi.org/10.18566/puente.v7n2.a03

Dalongaro, R. C., \& Froemming, L. M. (2012). La Satisfacción de Clientes como Estrategia de Marketing para la Venta. Book of Proceedings of the 7th International Conference on Industrial Engineering and Industrial Management. Conferencia llevada a cabo en el XVII Congreso de Ingeniería de Organización, Valladolid, España. Recuperado de: https://www.insisoc.org/CIO2013/papers/SP_01/ La Satisfacción de Clientes como Estrategia de Marketing para la Venta.pdf

Daza-Rodríguez, M. E. (2017). Servicio Al Cliente: Una Estrategia Gerencial Para Incrementar La Competitividad Organizacional En Empresas De Valledupar (Colombia). Revista de Investigación En Administración e Ingeniería, 7(1), 20-26. Recuperado de: http://revistas.udes.edu.co/ site/index.php/aibi/article/view/425 
Faría, M. C., Salazar, C., \& Castellano, M. I. (2017). Endomarketing: Estrategia dinamizadora para la responsabilidad social del sector universitario. Espacios, 38(1). Recuperado de: https://redivep.com/ sitio/wp-content/uploads/2017/02/Endomarketing-EstrategiaDinamizadora.pdf

García, A. (2016). Cultura de servicio en la optimización del servicio al cliente. Telos: Revista de Estudios Interdisciplinarios en Ciencias Sociales, 18(3), 381-398. Recuperado de: https://www.redalyc.org/ pdf/993/99346931003.pdf

Gutiérrez-Suarez, C., Sánchez, A. R., \& Garay, A. F. (2019). Direccionamiento Estratégico, Una Estrategia Organizacional Con Alto Impacto En El Desarrollo Laboral. Aibi Revista de Investigación, Administración e Ingeniería, 7(1), 8-15. Recuperado de: http://revistas.udes.edu.co/ site/index.php/aibi/article/view/544

Mojica Montoya, F. (2018). Factores de equidad en las unidades agrícolas familiares del municipio de La Calera. Bogotá: Editorial Fundación Universitaria San Mateo. Recuperado de https://palma.sanmateo. edu.co/

Sanz Del Vecchio, D., Crissien Borrero, T., García Guiliany, J., \& Patiño Villanueva, M. (2017). Marketing Educativo Como Estrategia De Negocio En Universidades Privadas. Desarrollo Gerencial, 9(1), 160. https://doi.org/10.17081/dege.9.1.2731

Vanessa, D., \& Duarte, L. (2018). Diferenciación en servicio al cliente: estrategia de posventa 1. Repositorio Universidad Militar Nueva Granada,1,1-32.Retrievedfromhttps://repository.unimilitar.edu.co/ bitstream/handle/10654/18183/LeguizamonDuarteDianaVanessa. pdf?sequence=1\&isAllowed=y

Vera Campuzano, N., \& Collins Ventura, N. V. (2018). El servicio al cliente como filosofía y factor de posicionamiento de las cooperativas de taxis. INNOVA Research Journal, 3(2), 71-82. https://doi. org/10.33890/innova.v3.n2.2018.413 